\title{
A systematic review of technology adoption frameworks and their applications
}

\author{
Sahil Koul ${ }^{1 *}$ and Ali Eydgahi
}

Abstract: The Technology Acceptance Model and the Theory of Planned Behavior have demonstrated pi oneering research efforts within the research domain of innovation adoption concerning new technologies. This study consolidated an in-depth literature review of both theoretical frameworks, covering their roots and development over the years within the scholarly community. Also, we reviewed the applicability of these frameworks within the context of emerging technologies of the information age. After a thorough literature review, we concluded that both frameworks are widely used and applicable to various emerging technologies and continue to remain instrumental in the research domain of innovation adoption.

Keywords: technology acceptance model; theory of planned behavior; emerging technologies; innovation adoption; innovation and society.

Submitted: August 22 $2017 /$ Approved: November $20^{\text {th }} 2017$

\section{Introduction}

Two theoretical frameworks, Technology Acceptance Model (TAM) and Theory of Planned Behavior (TPB), serve as the foundation of technology adoption studies within various contexts. TAM is a widely utilized theoretical framework for the assessment of how people make decisions regarding new technology adoption. TAM has frequently been used for information systems and other fields (Davis, 1989). TPB is highly recognized and significantly used for marketing research studies (Ajzen, 1991). As such, it is an appropriate model to use to address consumer acceptance of various technologies. Therefore, both TAM and TPB are useful when a study focuses on the potential adoption of an emerging technology. This review paper provides an in-depth examination of the theoretical frameworks of TAM and TPB. Further, the existing literature focused on innovation adoption for various emerging technologies highlights the application and significance of TAM and TPB models.

\section{Technology Acceptance Model}

The goal of TAM is to predict user acceptance and highlight potential design issues before users of the technology interact with the system (Dillon \& Morris, 1996; Mohd, Ahmad, Samsudin, \& Sudin, 2011). TAM was developed with support from IBM Canada and is rooted in the basic psychological theory known as the Theory of Reasoned Action (TRA; Ajzen \& Fishbein, 1980). As shown in Figure 1, TAM demonstrates a pioneering research effort by generating a framework for explaining behavioral intentions and actual behavior of users for new technology adoption.

Figure 1. TAM model. Adapted from Davis \& Venkatesh, 1996, p. 20.

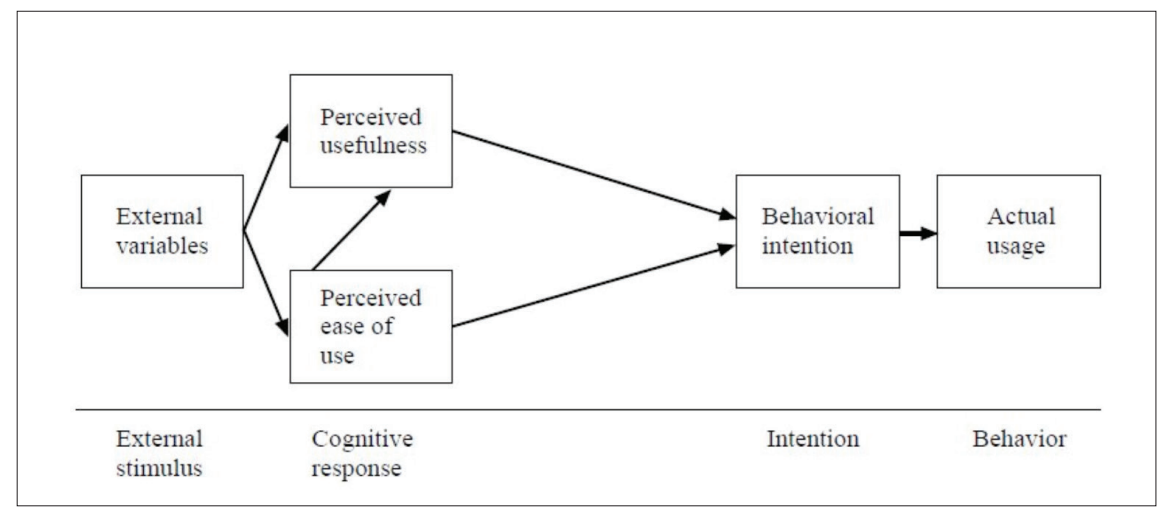

Perceived Usefulness (PU) and Perceived Ease of Use (PEOU) are the perceptions of the beliefs users hold about the system (Dillon \& Morris, 1996). Davis (1989) defined PU as "the degree to which a person believes that using a particular system would enhance his or her job performance" and PEOU as "the degree to which a person believes that using a particular system would be free of effort" (p. 3). The original study of TAM generated six highly reliable items for both PU and PEOU.

\section{Development of TAM}

Various researchers and practitioners have validated the robustness of the TAM instrument in different settings (Davis, 1993; Davis \& Venkatesh, 1996; Dillon \& Morris, 1996; Lee, Kozar, \& Larsen, 2003). Further, in a meta-analysis, Lee et al. (2003) explored 101 research articles and presented a progression map of TAM as shown below in figure 2 .

(1) College of Technology, Eastern Michigan University, 109 Sill Hall, Ypsilanti, Michigan 48197, USA. (2) School of Engineering Technology, Eastern Michigan University, 118 Sill Hall, Ypsilanti, Michigan 48197, USA.

*Correspondig author: skoul@emich.edu 
Figure 2. Progression of TAM. Adapted from Lee et al., 2003, p.755.

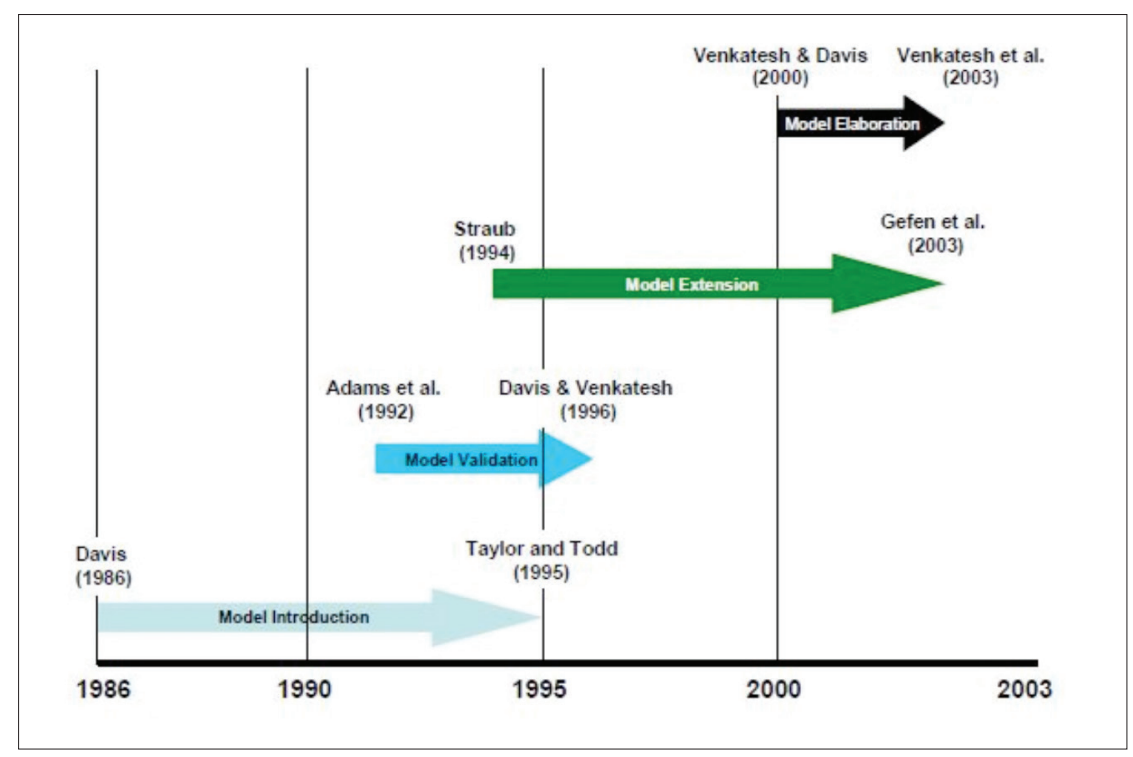

Venkatesh and Davis (2000), through four longitudinal studies, proposed an extension of the TAM model and established another novel model known as TAM2. This TAM2 model introduced cognitive and social influence processes as a way of measuring usage intentions and perceived usefulness. The results demonstrated that the TAM2 model accounted for $52 \%$ of the variance in usage intentions and $60 \%$ of the variance in usefulness perceptions (Venkatesh \& Davis, 2000). In another study, Venkatesh, Morris, Davis, and Davis (2003) formulated and validated an integrated model that, was an extension of TAM and termed it a 'Unified Theory of Acceptance and Use of Technology' (UTAUT). An adjusted R2 value of 70\% found with the UTAUT model outperformed all other previous user acceptance models. The authors concluded that, by utilizing their UTAUT model, interventions could be aimed in advance towards the population who are less inclined to adopt the new technology (Venkatesh et al., 2003). Figure 3 reflects the different extensions of the TAM model enhancements as presented by Holden and Karsh (2010).

Figure 3. Extensions of the TAM model. Adapted from Holden \& Karsh, 2010, p. 161

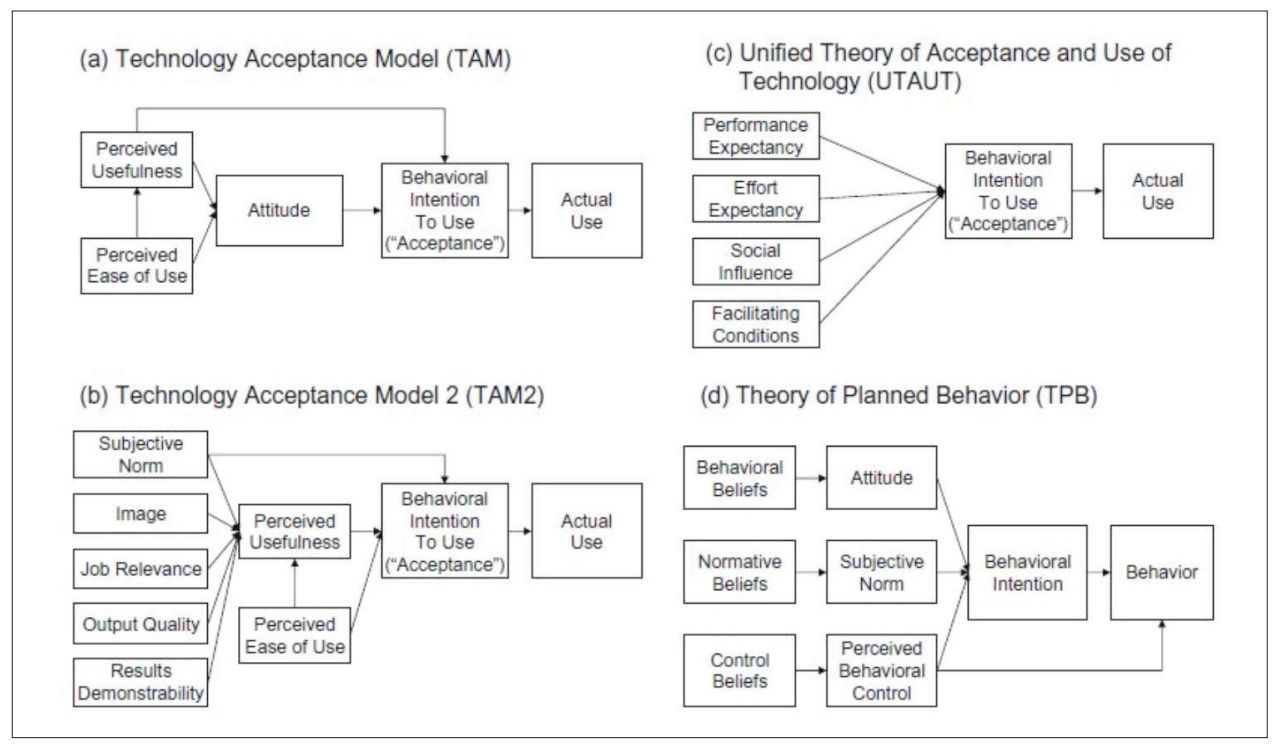

As per the meta-analysis conducted by Yousafzai, Foxall, and Pallister (2007a), the three major factors to which the widespread adoption of TAM can be attributed are a strong theoretical base and robust measurement scales, strong empirical support for the overall explanatory power of the model, and applicability in a wide range of systems and technologies. In this meta-analysis, the summary of 15 years of studies on TAM revealed a high correlation for the 'field setting' between PU, PEOU, and intention to use various technologies.

Among the few limitations reported in the literature regarding TAM, the most commonly reported limitation is related to self-reported usage (Lee et al., 2003). Furthermore, since TAM is used to predict 
the behavioral intention to accept technology, some researchers believe that there is not enough exposure to the technology before the assessment is carried out (Lee et al., 2003). Moreover, the original model of TAM did not include social influence (Ghazizadeh, Lee, \& Boyle, 2012), but the technology under study was of an individualistic nature and independent of the use of others (Dillon \& Morris, 1996).

\section{Theory of Planned Behavior}

This theory was an improvement upon the TRA (Ajzen \& Fishbein, 1980), which looked at predicting individual behavior in volitional situations (Sparks \& Shepherd, 1992). TPB focuses mainly on predicting planned human behavior and incorporates the construct of perceived behavioral control (Li, 2010; Montano \& Kasprzyk, 2015; Sparks \& Shepherd, 1992). The literature has presented sufficient evidence that TPB has an enhanced capability of predicting behavioral intention by adding the perceived behavioral control construct (Madden, Ellen, \& Ajzen, 1992). A study comparing the models of TRA and TPB for ten different behavioral scenarios revealed that TPB provided a significantly enhanced explanation of behavioral intentions over TRA due to the inclusion of the perceived behavioral control construct (Madden et al., 1992). Also, Madden et al. (1992) claimed that this increased enhancement is positively correlated to the magnitude of perceived behavioral control.

When individuals have time to plan for their behavior, in order to predict their behavior, we need to understand their intention towards performing that behavior (predictor), which is the summation of Attitude, Subjective Norms, and Perceived Behavior control constructs as shown in Figure 4. Also, if two or more of these constructs are not supporting the behavioral intention, then the likelihood of actually performing that behavior decreases significantly.

Figure 4. Theory of Planned Behavior model. Adapted from Ajzen, 1991, p. 182.

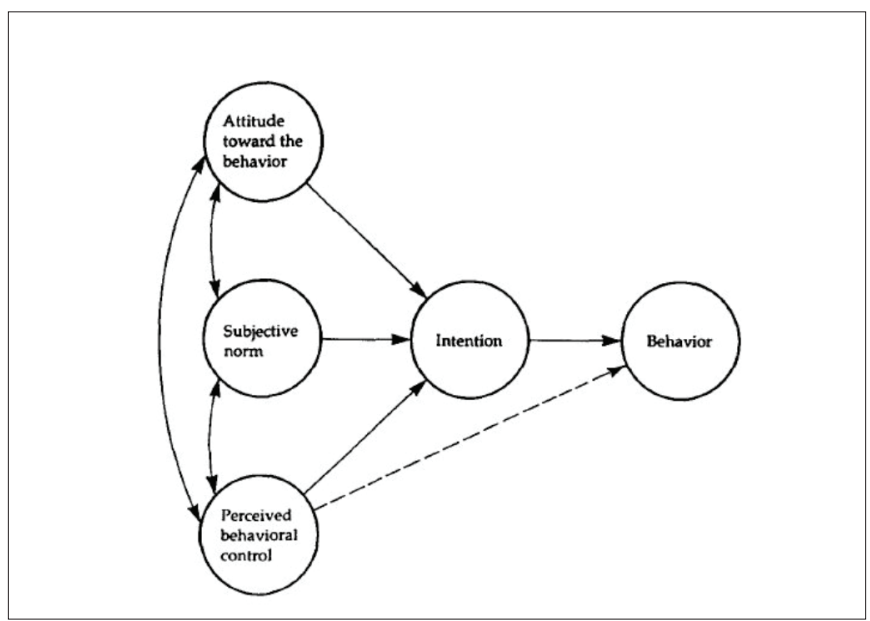

Attitude: The construct of attitude is an individual's own opinion about a given situation. This opinion is formulated through selfanalysis gathered via an individual's behavioral beliefs and outcome evaluations (Mathieson, 1991). Attitudes are found to be positive or negative (Agarwal, 2000; Orbell, Hodgkins, \& Sheeran, 1997).
Subjective Norms: This construct constitutes the external societal forces acting upon an individual (Agarwal, 2000; Mathieson, 1991; Orbell et al., 1997), such as cultural, referent, and group elements.

Perceived Behavioral Control: This construct reflects if an individual is faced with a difficult or easy task for a given situation (Agarwal, 2000; Orbell et al., 1997) and can be dependent on the available skills and resources required to formulate behavioral intentions (Dillon \& Morris, 1996).

\section{Development of TPM}

TPB has followed a trajectory similar to the key milestones of TAM development (Venkatesh, Davis, \& Morris, 2007). Much of the early research on TPB focused on replicating the results of the original study in different settings, cultures, and for a variety of behaviors (Venkatesh et al., 2007). After that, research focused on establishing the predictive validity of TPB and then eventually competing theoretical perspectives to enhance the richness of the original model (Venkatesh et al., 2007). One such refinement to the original model was achieved by the fusion of TPB and TAM into a novel decomposed model of TPB (DTPB; Taylor \& Todd, 1995a; Taylor \& Todd, 1995c). The DTPB model presented a more thorough understanding of behavioral intention and a slightly more enhanced explanatory power than the TPB (Taylor \& Todd, 1995a; Taylor \& Todd, 1995c). The DTPB model distinctly helped in enhancing understanding of not only the design aspects but also the factors relevant to the implementation of the new technology under study.

The scholarly community debates about the reasonable expectation of correlation among TPB constructs. Prediction of behavioral intentions is at the core of the TPB model, and a reasonable expectation regarding the correlation among various constructs of this framework should be around 0.60 (Ajzen, 2011). TPB is a well-known theory to predict adoption intentions in an organizational setting (Taylor \& Todd, 1995b). It is not possible, however, to include all the different constructs and variables in one study (Conner \& Armitage, 1998). Hence, reasonable expectation is to choose the constructs and variables that are most applicable to the nature of the behavior under study.

\section{Emerging Technologies as Applications of TAM and TPB}

The results of the meta-analysis conducted by Arts et al. (2011) revealed important differences between the stages of behavioral intentions and actual behavior. The actual behavior of innovation adoption is more prominent with less complex innovations that reflect higher relative advantage than innovations that are more complex. Also, fewer studies in non-work settings are available in the innovation adoption literature than compared to the work setting (Lu, Yao, \& Yu, 2005). Therefore, predicting non-work-related consumer behavior with the help of typical adoption frameworks, such as TAM, TPB, and UTAUT, is worthy of examination (Lu et al., 2005).

TAM was utilized in a study involving 866 Singaporean students from the National University to investigate the consumer attitudes towards 
using mobile commerce (Yang, 2005). Regression analysis revealed that PU influences the attitude towards using mobile commerce. This study found that males perceive mobile commerce more favorably than females do. Similarly, another study comparing traditional and advanced mobile services linked the antecedents of behavioral intentions, PU and PEOU, with Social Influence (SI) and perceived benefits (López-Nicolás, Molina-Castillo, \& Bouwman, 2008). This study, conducted among 542 Dutch consumers, validated the application of TAM, and predicted acceptance related to advanced mobile services. The authors of this study pointed out that SI might not be as important in voluntary situations as it is in mandatory settings (López-Nicolás et al., 2008).

Drennan, Kennedy, and Pisarski (2005) used PU and PEOU as antecedents to student satisfaction for online learning in management courses and utilizing structure equation modeling. The results of this study confirmed that student satisfaction had a relationship with positive perceptions of online learning technology. This study demonstrated an example of TAM's PU and PEOU constructs successfully establishing a relationship with the intention to use online learning technology. Similarly, Lane and Coleman (2012) applied TAM by looking at PU and PEOU of social networking media, such as Facebook and MySpace, within a group of business students at a U.S. regional university. The results of this study found that higher PEOU led to higher PU, which ultimately led to a higher use of social networking media. Further, Park, Kim, Shon, and Shim (2013), in their study on Smartphone usage in South Korea, applied TAM. They did an in-person survey of 852 individuals, which helped them validate TAM for the context of Smartphone usage in South Korea. However, in contrast to the studies above, Horton, Buck, Waterson, and Clegg (2001) looked at intranet usage in two organizations located in the United Kingdom and found mixed results with applying TAM as a tool in understanding intranet usage.

Innovation adoption study, such as wireless internet services through mobile technology, has revealed a significant relationship between social influences and adoption intentions (Lu et al., 2005). By collecting data from $357 \mathrm{MBA}$ students at Texas A\&M University, this study helped advance the understanding of the theoretical determinants of early innovation adoption. Utilizing structural equation modeling, the study revealed the causal relationships between the constructs under study. Moreover, sometimes an innovation can become a symbolic enhancement agent of one's social status (Kulviwat et al., 2009), similar to the behavior reported in young Asians and their use of Smartphones (Lu et al., 2005). In the literature, early adopters are sometimes also known as prompters (Kim \& Park, 2011). Besides often making a recommendation, these referent sources even sometimes acquire the technology for other individuals, which in turn influences an individual's attitude of experiencing the innovation (Kim \& Park, 2011).

Similarly, in their study on the adoption of high-tech innovations, Kulviwat et al. (2009) concluded that positive SI through positive attitude has a positive influence on the adoption intention of hightech innovations. This study found an indirect relationship between
SI and adoption intentions. If an organization convinces its consumers that a relevant group endorses a particular innovation, then the organization can potentially influence individuals' attitudes towards that innovation (Kulviwat et al., 2009). Structural equation modeling through a large, Midwestern United States university sample established the relationship among the constructs under study. Furthermore, the relationship between SI and adoption intention was found to be more pronounced when the innovation was consumed publicly (Kulviwat et al., 2009). The authors recommended that further studies on innovation adoption should incorporate SI into a full model of TAM, especially in the context of consumer behavior model and not within the boundaries of organizational environment.

Jansson, Marell, and Nordlund (2010) studied a total of 1,832 alternative fuel vehicle adopters and non-adopters and focused on analyzing their willingness to adopt eco-friendly car technology. The authors found that norms, beliefs, values, and strength of habits determined willingness to adopt eco-friendly car technology. They pointed out that adopters may serve as useful communicators to other individuals, informing the others of their adoption decision. Also, it is likely that, once adopters have adopted the innovation, they are more likely to be open to future innovations as compared to non-adopters (Jansson et al., 2010). Moreover, in pursuit of applying TPB to driver's behavioral intentions to commit specific driving violations, Parker, Manstead, Stradling, Reason, and Baxter (1992) conducted a study on a stratified sample of drivers. The results of this study supported the use of perceived behavioral control, which significantly increased the variance explained in the behavioral intentions of driving violations. Also, the relationship of subjective norm construct and behavioral intentions was found to be stronger than the relationship between attitude and behavioral intentions.

Similarly, in their study on the application of TPB, Ajzen and Driver (1992) found that their model supported the behavior in the context of leisure activities. Regression-based analysis of over 140 students formed the core of the main study that validated their model and its utility in leisure activities. Further, in another attempt to apply TPB, Taylor and Todd (1995b) surveyed 790 consumers at a shopping mall to compare four models, which included three versions of TPB and TRA. These consumers were potentially deciding to adopt the technology VCRPlus, which was new at the time of the study, and the participants were limited to 18 years or older with a VCR in their household. The results from this study discovered that all four of the models exhibited coherent fit to the data (Taylor \& Todd, 1995b). Likewise, Bamberg, Ajzen, and Schmidt (2003) conducted a longitudinal study on the application of TPB as a conceptual framework for the choice of travel mode. The study examined the effects of the intervention (prepaid bus tickets) on the increased usage of bus service among college students. The intervention in this study influenced all three determinants of behavioral intention and doubled the number of students taking the bus to school. The TPB model did successfully predict behavior in both pre and post intervention cases (Bamberg et al., 2003).

In another study on internet purchasing, George (2004) found that the respondents who believed in their self-abilities and considered the 
internet trustworthy were more apt to make an online purchase than those respondents who did not possess these beliefs. Once again, the author of this study established the robustness of TPB to explain internet-purchasing behavior. Moreover, on the intention to adopt internet banking in Taiwan, researchers compared TPB (pure and decomposed) and TRA with 425 respondents in their sample (Shih \& Fang, 2004). Structural equation modeling analysis revealed that all three of the models provided a decent explanation of the data. The decomposed TPB provided a slightly higher explanation of the variance in behavioral intention, subjective norms, and attitude towards the consumer's adoption of internet banking in Taiwan. Finally, Pavlou and Fygenson (2006), in their longitudinal study, attempted to explain and predict consumers' adoption of e-commerce and validated the predictive power of TPB. The results from this study showed that e-commerce adoption is the function of both product purchasing and information gathering.

\section{Final Remarks}

Research within the field of innovation adoption often presents a challenge regarding the scarcity of similar studies and consumers' innovation inexperience (Cooper, 1998). With the increase in technological dependence in our lives and global economic interdependence, several researchers associated with academia and industry have been actively involved in studying consumers' adoption intentions of various technologies (Arts, Frambach, \& Bijmolt, 2011; Kulviwat, Bruner, \& Al-Shuridah, 2009). Figure 5 below shows the consolidated model representing a literature overview on various applications of TAM and TPB.

Figure 5. Model depicting various applications of TAM and TPB.

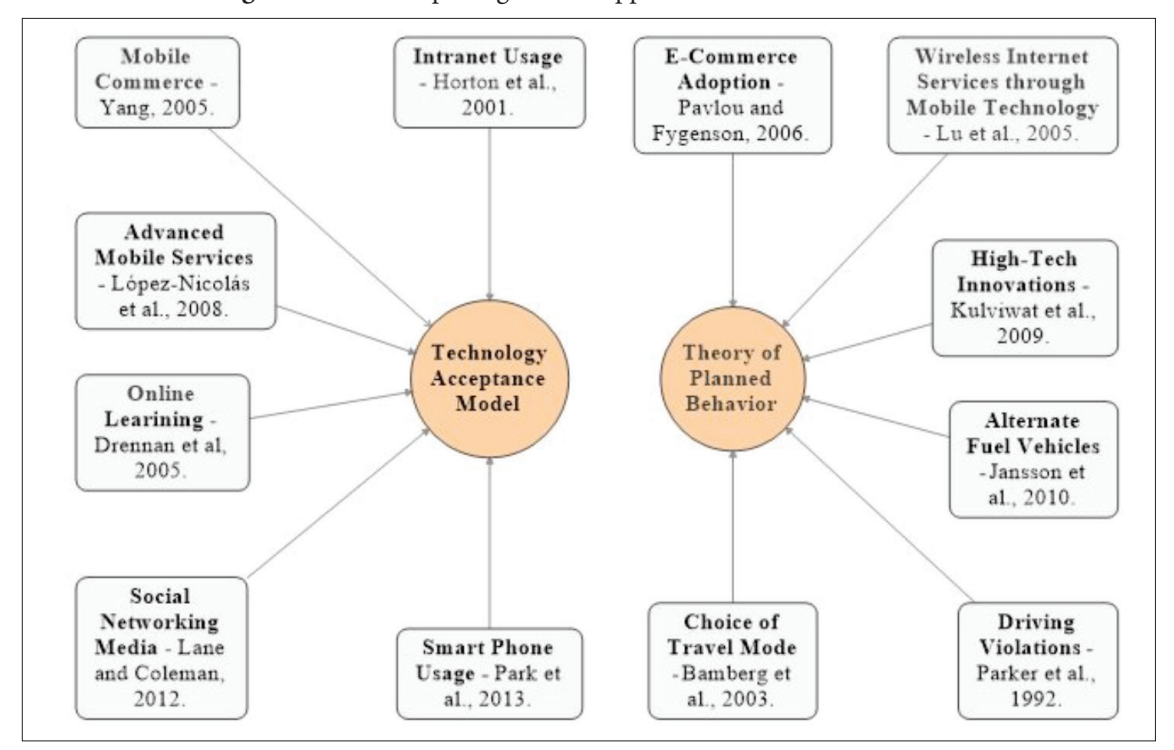

The dynamics of the relationship between humans and automation is critical to performance and survival of emerging technologies (Ghazizadeh et al., 2012). Both TAM and TPB will continue to serve as the fundamental means for researchers seeking to study the factors influencing consumers' adoption intentions of various technologies. The literature reveals a wide variety of applications for both of these frameworks across multiple cultures, geographies, and different contexts.

\section{References}

Agarwal, R. (2000). Individual acceptance of information technologies. In Framing the domains of IT management: Projecting the future through the past (pp. 85-104). Cincinnati, OH: Pinnaflex. Retrieved from https://www.researchgate.net/publication/265746136_Chapter_6_Individual_Acceptance_of_Information_Technologies

Ajzen, I. (1991). The Theory of Planned Behavior. Organizational Behavior and Human Decision Processes, 50(2), 179-211. https://doi.org/10.1016/0749-5978(91)90020-T
Ajzen, I. (2011). The Theory of Planned Behaviour: Reactions and reflections. Psychology \& Health, 26(9), 1113-1127. https://doi.org/10.1 080/08870446.2011.613995

Ajzen, I., \& Driver, B. L. (1992). Application of the Theory of Planned Behavior to leisure choice. Journal of Leisure Research, 24(3), 207-212. Retrieved from http://search.proquest.com/openview/ fedcb663a9890ab8a1ed8184dde8d333/1 ?pqorigsite=gscholar\&c $\mathrm{bl}=1816610$

Ajzen, I., \& Fishbein, M. (1980). Understanding attitudes and predicting social behaviour. Englewood Cliffs, NJ: Prentice-Hall. Retrieved from http://www.citeulike.org/group/38/article/235626

Arts, J. W. C., Frambach, R. T., \& Bijmolt, T. H. A. (2011). Generalizations on consumer innovation adoption: A meta-analysis on drivers of intention and behavior. International Journal of Research in Marketing, 28(2), 134-144. https://doi.org/10.1016/j.ijresmar.2010.11.002 
Bamberg, S., Ajzen, I., \& Schmidt, P. (2003). Choice of travel mode in the Theory of Planned Behavior: The roles of past behavior, habit, and reasoned action. Basic and Applied Social Psychology, 25(3), 175-187. https://doi.org/10.1207/S15324834BASP2503_01

Conner, M., \& Armitage, C. J. (1998). Extending the Theory of Planned Behavior: A review and avenues for further research. Journal of Applied Social Psychology, 28(15), 1429-1464.

https://doi.org/10.1111/j.1559-1816.1998.tb01685.x

Cooper, J. R. (1998). A multidimensional approach to the adoption of innovation. Management Decision, 36(8), 493-502. https://doi.org/10.1108/00251749810232565

Davis, F. D. (1989). Perceived usefulness, perceived ease of use, and user acceptance of information technology. MIS Quarterly, 13(3), 319-340. https://doi.org/10.2307/249008

Davis, F. D. (1993). User acceptance of information technology: System characteristics, user perceptions and behavioral impacts. International Journal of Man-Machine Studies, 38(3), 475-487. https://doi.org/10.1006/imms.1993.1022

Davis, F. D., \& Venkatesh, V. (1996). A critical assessment of potential measurement biases in the Technology Acceptance Model: Three experiments. International Journal of Human-Computer Studies, 45(1), 19-45. https://doi.org/10.1006/ijhc.1996.0040

Dillon, A., \& Morris, M. G. (1996). User acceptance of new information technology: Theories and models. Annual Review of Information Science and Technology, 14(4), 3-32. Retrieved from http://hdl.handle.net/10150/105584

Drennan, J., Kennedy, J., \& Pisarski, A. (2005). Factors affecting student attitudes toward flexible online learning in management education. The Journal of Educational Research, 98(6), 331-338. https://doi.org/10.3200/JOER.98.6.331-338

George, J. F. (2004). The Theory of Planned Behavior and internet purchasing. Internet Research, 14(3), 198-212. https://doi. org/10.1108/10662240410542634

Ghazizadeh, M., Lee, J. D., \& Boyle, L. N. (2012). Extending the Technology Acceptance Model to assess automation. Cognition, Technology \& Work, 14(1), 39-49. https://doi.org/10.1007/s10111-011-0194-3

Holden, R. J., \& Karsh, B. T. (2010). The Technology Acceptance Model: Its past and its future in health care. Journal of Biomedical Informatics, 43(1), 159-172. https://doi.org/10.1016/j.jbi.2009.07.002

Horton, R. P., Buck, T., Waterson, P. E., \& Clegg, C. W. (2001). Explaining intranet use with the Technology Acceptance Model. Journal of Information Technology, 16(4), 237-249. https://doi.org/10.1080/02683960110102407
Jansson, J., Marell, A., \& Nordlund, A. (2010). Green consumer behavior: Determinants of curtailment and eco innovation adoption. Journal of Consumer Marketing, 27(4), 358-370. https://doi. org/10.1108/07363761011052396

Kim, S. H., \& Park, H. J. (2011). Effects of social influence on consumers' voluntary adoption of innovations prompted by others. Journal of Business Research, 64(11), 1190-1194. https://doi.org/10.1016/j. jbusres.2011.06.021

Kulviwat, S., Bruner, G. C., \& Al-Shuridah, O. (2009). The role of social influence on adoption of high tech innovations: The moderating effect of public/private consumption. Journal of Business Research, 62(7), 706-712. https://doi.org/10.1016/j.jbusres.2007.04.014

Lane, M., \& Coleman, P. (2012). Technology ease of use through social networking media. Journal of Technology Research, 3, 1-12. Retrieved from

http://search.proquest.com/openview/070df63945c48ea6c4102942af d61ff8/1.pdf?pq-origsite $=$ gscholar $\& c b l=237733$

Lee, Y., Kozar, K. A., \& Larsen, K. R. (2003). The Technology Acceptance Model: Past, present, and future. Communications of the Association for Information Systems, 12(50), 750-782. Retrieved from http://aisel.aisnet.org/cgi/viewcontent.cgi? article=3217\&context=cais

Li, L. (2010). A critical review of technology acceptance literature. Grambling State University, 19. Retrieved from http://www.swdsi.org/swdsi2010/sw2010_preceedings/papers/pa104.pdf

López-Nicolás, C., Molina-Castillo, F. J., \& Bouwman, H. (2008). An assessment of advanced mobile services acceptance: Contributions from TAM and diffusion theory models. Information \& Management, 45(6), 359-364. https://doi.org/10.1016/j.im.2008.05.001

Lu, J., Yao, J. E., \& Yu, C. S. (2005). Personal innovativeness, social influences and adoption of wireless internet services via mobile technology. The Journal of Strategic Information Systems, 14(3), 245-268. https://doi.org/10.1016/j.jsis.2005.07.003

Madden, T. J., Ellen, P. S., \& Ajzen, I. (1992). A comparison of the Theory of Planned Behavior and the Theory of Reasoned Action. Personality and Social Psychology Bulletin, 18(1), 3-9.

https://doi.org//10.1177/0146167292181001

Mathieson, K. (1991). Predicting user intentions: Comparing the Technology Acceptance Model with the Theory of Planned Behavior. Information Systems Research, 2(3), 173-191. https://doi.org/10.1287/isre.2.3.173

Mohd, F., Ahmad, F., Samsudin, N., \& Sudin, S. (2011). Extending the Technology Acceptance Model to account for social influence, trust and integration for pervasive computing environment: A case study in university industry. American Journal of Economics and Business Administration, 3(3), 552-559. Retrieved from http://search. proquest.com/openview/bcb1c53cdac2c8892bbe001a94052176/1? pq-origsite $=$ gscholar $\& \mathrm{cbl}=1216358$ 
Montano, D. E., \& Kasprzyk, D. (2015). Theory of Reasoned Action, Theory of Planned Behavior, and the Integrated Behavioral Model. Retrieved from https://books.google.com/books?hl=en\&lr=\&id=9BQ WCgAAQBAJ\&oi=fnd\&pg=PA95\&dq=theory+of + planned +behavi or\&ots=ecP991xM9_\&sig=7fEDSCmujDoilzSr-NbjuGLy4e4

Orbell, S., Hodgkins, S., \& Sheeran, P. (1997). Implementation intentions and the Theory of Planned Behavior. Personality and Social Psychology Bulletin, 23(9), 945-955. https://doi. org/10.1177/0146167297239004

Park, N., Kim, Y. C., Shon, H. Y., \& Shim, H. (2013). Factors influencing smartphone use and dependency in South Korea. Computers in Human Behavior, 29(4), 1763-1770. https://doi.org/10.1016/j. chb.2013.02.008

Parker, D., Manstead, A. S., Stradling, S. G., Reason, J. T., \& Baxter, J. S. (1992). Intention to commit driving violations: An application of the Theory of Planned Behavior. Journal of Applied Psychology, 77(1), 94-101. https://doi.org/10.1037/0021-9010.77.1.94

Pavlou, P. A., \& Fygenson, M. (2006). Understanding and predicting electronic commerce adoption: An extension of the Theory of Planned Behavior. MIS Quarterly, 30(1), 115-143. Retrieved from http://www.jstor.org/stable/25148720

Shih, Y., \& Fang, K. (2004). The use of a decomposed Theory of Planned Behavior to study internet banking in Taiwan. Internet Research, 14(3), 213-223. https://doi.org/10.1108/10662240410542643

Sparks, P., \& Shepherd, R. (1992). Self-identity and the Theory of Planned Behavior: Assessing the role of identification with green consumerism. Social Psychology Quarterly, 55(4), 388-399. https://doi.org/10.2307/2786955

Taylor, S., \& Todd, P. (1995a). Assessing IT usage: The role of prior experience. MIS Quarterly, 19(4), 561-570. https://doi.org/10.2307/249633

Taylor, S., \& Todd, P. (1995b). Decomposition and crossover effects in the Theory of Planned Behavior: A study of consumer adoption intentions. International Journal of Research in Marketing, 12(2), 137155. https://doi.org/10.1016/0167-8116(94)00019-K

Taylor, S., \& Todd, P. (1995c). Understanding information technology usage: A test of competing models. Information Systems Research, 6(2), 144-176. https://doi.org/10.1287/isre.6.2.144

Venkatesh, V., \& Davis, F. D. (2000). A theoretical extension of the Technology Acceptance Model: Four longitudinal field studies. Management Science, 46(2), 186-204. https://doi.org/10.1287/ mnsc.46.2.186.11926

Venkatesh, V., Davis, F. D., \& Morris, M. G. (2007). Dead or alive? The development, trajectory and future of technology adoption research. Journal of the Association for Information Systems, 8(4), 267-286.
Retreievd from

http://search.proquest.com/openview/3ccfb894c4987572e5b9c4f899

3b4c63/1 ?pq-origsite $=$ gscholar $\& \mathrm{cbl}=26427$

Venkatesh, V., Morris, M. G., Davis, G. B., \& Davis, F. D. (2003). User acceptance of information technology: Toward a unified view. MIS Quarterly, 27(3), 425-478. Retrieved from http://www.jstor.org/stable/30036540

Yang, K. C. C. (2005). Exploring factors affecting the adoption of mobile commerce in Singapore. Telematics and Informatics, 22(3), 257-277. https://doi.org/10.1016/j.tele.2004.11.003

Yousafzai, S. Y., Foxall, G. R., \& Pallister, J. G. (2007). Technology acceptance: A meta analysis of the TAM: Part 1. Journal of Modelling in Management, 2(3), 251-280. https://doi. org/10.1108/17465660710834453

\section{Biography}

Sahil Koul is currently a Ph.D. candidate in the College of Technology at Eastern Michigan University, Michigan, USA. He received his Master's of Science degree in Automotive Engineering from Lawrence Technological University, Michigan, USA. His research interests are in interdisciplinary areas of automotive technologies, including driverless car technology, technology acceptance and diffusion of emerging technologies, and examining socio-technological interactions. He has over ten years of experience working within the automotive domain and currently works as an engineering manager for a large North American automotive accessory manufacturer.

Ali Eydgahi started his career in higher education as a faculty member at the Rensselaer Polytechnic Institute in 1985. Since then, he has been with the State University of New York, University of Maryland Eastern Shore, and Eastern Michigan University. During 2006-2010, he was Chair of the Department of Engineering and Aviation Sciences, Founder and Director of the Center for 3-D Visualization and Virtual Reality Applications, and Technical Director of the NASAfunded MIST Space Vehicle Mission Planning Laboratory at the University of Maryland Eastern Shore. In 2010, he joined Eastern Michigan University as an Associate Dean in the College of Technology and currently is a Professor in the School of Engineering Technology. He has extensive experience in curriculum and laboratory design and development. Dr. Eydgahi has served as a member of the Board of Directors of Tau Alpha Pi and as a member of advisory and editorial boards for many international journals in engineering and technology. Also, he has served as a member of the review panel for NASA and Department of Education, as a regional and chapter chairman of IEEE, SME, and ASEE, and as a session chair and a member of scientific and international committees for many international conferences. 
